\title{
Traumatic Brain Injury (TBI): A Guide for Probation Officers
}

Jerrod Brown ${ }^{1,2,3^{*}}$, Brooke Luckhardt ${ }^{4}$, Diane Harr ${ }^{1}$, Thomas Poser ${ }^{3}$ and Amanda Fenrich ${ }^{5}$

${ }^{1}$ Concordia University, St. Paul, MN, USA

${ }^{2}$ Pathways Counseling Center, St. Paul, MN, USA

${ }^{3}$ The American Institute for the Advancement of Forensic Studies, St. Paul, MN, USA

${ }^{4}$ Associates in Physical Medicine and Rehabilitation, P.C., Ypsilanti, Michigan, USA

${ }^{5}$ Washington State Department of Corrections, Monroe, WA, USA

"Corresponding author: Jerrod Brown, Pathways Counseling Center, 1919 University Ave. W. Suite 6 St. Paul MN, USA, Tel: +1651-641-1555; E-mail: jerrod01234brown@live.com

Rec date: January 30, 2018; Acc date: March 19, 2018; Pub date: March 21, 2018

Copyright: @ 2018 Brown J, et al. This is an open-access article distributed under the terms of the creative commons attribution license, which permits unrestricted use, distribution, and reproduction in any medium, provided the original author and source are credited.

\begin{abstract}
Referred to as a "silent epidemic," traumatic brain injuries (TBI) are disruptions in normal brain functions caused by an external force to the head (Center for Disease Control, 2017). Ranging from mild to severe in nature, TBl's can result in physical, cognitive, emotional, social, personality, adaptive, and behavioral changes in an individual. These devastating symptoms render individuals with TBI's disproportionately likely to become involved in the criminal justice system. Once arrested, the symptoms of TBI make it difficult to make important legal decisions, stand trial, and meet the conditions of probation, which results in an elevated risk for rearrests relative to those individuals without a TBI. Despite these difficulties, probation officers have the potential to help improve outcomes for clients with TBI. In particular, these professionals can help ensure that clients with TBI are referred to proper assessment and diagnosis, individualized supervision that accounts for their strengths and weaknesses, and receive appropriate treatment and medical assistance. As such, this article is intended to raise awareness of the challenges of TBI in a probation setting and offer tips, strategies, and solutions for probation officers working with this clientele.
\end{abstract}

Keywords: Criminal justice; Intervention; Probation; Screening; Traumatic brain injury

\section{Introduction}

\section{Traumatic-brain injury (TBI): An overview}

With a high incidence rate and often undiagnosed, traumatic brain injuries (TBI) have been referred to as a "silent epidemic" [1-7]. These can be defined as a disruption in the normal function of the brain caused by a bump, blow, jolt, or penetrating injury to the head by an external force [1]. The frontal lobes of the brain are particularly vulnerable to acceleration-deceleration forces resulting from the abrupt head movement that occurs in motor vehicle accidents or falls, causing diffuse axonal injury that can affect many brain structures [8].

The seriousness of a traumatic brain injury can range from mild to severe and result in short-term to permanent alterations in brain functioning. Such an injury can result in physical, cognitive, emotional, social, personality, adaptive, and behavioral changes in an individual. Traumatic brain injury risk has been linked to learning disorders, poor judgment, impulsivity, socioeconomic status, and gender. Males are twice as likely to suffer a traumatic brain injury as females [9]. Inaccurate diagnosis and co-occurring psychiatric and substance use disorders often exacerbate the symptoms of TBI's. A diagnosis of TBI has forensic importance and many researchers warn that subjective complaints in the mild TBI patients should not be treated as insignificant [10].

Due these devastating symptoms, individuals with TBI's are disproportionately likely to become involved in the criminal justice system [11]. In fact, prevalence rates are drastically higher than the $8.5 \%$ observed in the general population. Although prevalence rates of TBI appear to vary by age, rates of $60 \%$ have been observed in adult offenders [12] and 30\% in juvenile offenders [13]. In their metaanalysis, reported prevalence rates of $64 \%$ and $70 \%$ in male and female offenders, respectively.

Once arrested, individuals with TBI often have trouble navigating the criminal justice system. This includes a proneness to suggestibility, confabulation, poor legal decisions like waiving legal rights, and false confessions. During trials, defendants with TBI are often less equipped to assist their lawyers with implementing a legal defense and may be more likely to receive a harsher sentence or be wrongfully convicted of a crime [5]. After conviction, individuals with TBI are more likely to have continued involvement in the criminal justice system, including an increase in rearrests relative to those individuals without a TBI.

Part of the reason for this elevated likelihood of recidivism may be that individuals with TBI are not well equipped to meet the requirements of community supervision (i.e., probation or parole) [14]. For instance, a sentence of probation means that an individual will be supervised in the community for a given time frame, rather than incarcerated. This supervision is centered on an agreement that the individual will meet certain requirements during their term of probation. Not only is the individual required to report to their probation officer at regular intervals, but the individual may be required to receive psychological or substance use treatment, abstain from the use of drugs, perform community service, avoid contact with any victims, undergo electronic monitoring, maintain employment, and pay restitution and legal fees. Unfortunately, these requirements will likely be difficult to comply with for someone who suffers from 
many of the impairments that characterize TBI. For example, memory impairments may make it difficult to show up on time for probation and treatment appointments. Additionally, persons with a history of TBI have higher recidivism rates due to impulsivity and anosognosia, the inability to foresee the consequences of their actions [15]. As a result, probationers with a history of TBI are 1.57 times more likely than other offenders to be rearrested within 12 months [4].

Although there is a lack of resources in the areas of interventions, preventative measures, and transition services for those with a TBI in the criminal justice system [16], probation officers have the potential to break this vicious cycle. While it is difficult to detect if someone has suffered a traumatic brain injury, it is important to understand the signs and symptoms, so a probationer may receive the appropriate services and supports to be successful on probation and reintegrate safely back into the community. Once recognized, these professionals can help ensure that clients with TBI receive proper assessment, individualized treatment plans, and seamless care during reintegration into society [17]. Clients with TBI can benefit from supervision within the Risk-Needs-Responsivity framework, where their individual risks and needs are identified with a validated risk assessment tool and then systematically addressed in a way that is responsive to their skills and abilities [18]. This framework exists within an evidence-based platform which has been shown to effectively reduce recidivism rates. Furthermore, program fidelity is considered a necessary part of the Risk-Needs-Responsivity framework of corrections [19]. Probation officers should be continually trained and assessed on their effective delivery of correctional programming. This could include the incorporation and ongoing assessment of modeling, role plays, and motivational interviewing techniques. Nonetheless, many probation officers are unfamiliar with TBI and how to assist clients with this issue. Training on the implementation of these skills and techniques would help increase compliance and success for the probationer. As such, this article is intended to raise awareness of the challenges of TBI in probation settings and offer tips, strategies, and solutions for probation officers working with this clientele.

\section{Literature Review}

The following are key points that are advised to take into consideration when dealing with probationers who may potentially have a traumatic brain injury.

\section{Adaptive functioning}

Individuals with TBI often suffer from impairments in adaptive functioning. This ability requires a mix of social (e.g., communication) and cognitive (e.g., attention and memory) skills. Individuals with adaptive functioning limitations often have difficulty taking care of themselves, complying with social responsibilities, and solving problems and challenges that come up in everyday life [20,21]. Additionally, TBI may affect every day functioning in terms of mobility and safe driving. Lifetime TBI is associated with $75 \%$ higher odds of collision involvement due to cognitive and/or mood factors [22]. As a result, individuals with TBI and adaptive functioning impairments are not only characterized by poor educational and occupational performance, but also present challenges on community supervision [23]. In fact, many of these individuals may be ill equipped to fulfill and maintain compliance with the conditions of probation. For example, it is difficult for clients with TBI and adaptive functioning impairments to follow simple directions and regularly show up on time for appointments. To limit the harmful consequences of TBI, probation officers should be aware of these potential issues and meet them with patience and flexibility.

\section{Co-occurring disorders}

TBI can be comorbid with an array of mental health issues including mood disorders, affective dysregulation, substance use, and changes in personality. For example, disorders such as depression, anxiety, and post-traumatic stress disorder (PTSD) are common among individuals with TBI [17]. More than $40 \%$ of patients impacted by TBI experience at least one recorded psychiatric diagnosis compared with $20 \%$ of the non-TBI population [24]. Post traumatic brain injury neuropsychiatric disorders, such as major depression and anxiety disorders, are associated with long term decreased function and quality of life, regardless of injury severity or time elapsed since injury [25]. Further, self-harm and suicide rates are higher among individuals with a TBI than in the general population. Persons with traumatic brain injury also have a higher frequency of suicide attempts, $8.1 \%$ versus $1.9 \%$ in the general population [26]. All these cooccurring issues can complicate the supervision and treatment of clients in the criminal justice system. When possible, these clients with TBI should be placed on specialty caseloads that are supervised by officers who have experience working with similar clients and knowledge of mental health, co-occurring disorders, and available resources. Probation officers should be aware of and trained on suicide warning signs, risk factors, and interventions. If probation officers determine that a probationer has any of these mental health issues, they should attempt to gather more information to see if the client suffers from symptoms associated with TBI and refer the client for formal assessment and evaluation.

\section{Suicide}

Deficits associated with TBI have been linked to self-harm, suicidal ideation, and suicidal behaviors in a review of 48 studies [27]. Simpson and Tate report that 21 to $22 \%$ of individuals with TBI experience suicidal ideation and $18 \%$ of the individuals with severe TBI go on to attempt suicide [28]. Similarly, Silver, Kramer, Greenwald, and Weissman found that those who suffered from a loss of consciousness due to a blow to the head are at least 4 times as likely to attempt suicide as individuals without this experience. There is an elevated rate of suicide completion for this population too [29]. Suicidal ideation within this population is up to 10 times higher for people without a high school education than people with similar education level in the general population [30]. Further, research suggests that the association between TBI and suicide does not diminish with time; as theory found the suicide rate among individuals with TBI was consistent across a 15year follow-up period [31]. This association between TBI and suicide is only exacerbated by co-occurring mood and substance use disorders $[32,33]$. Other factors that increase the risk of post-TBI suicidal behaviors include the severity of the TBI and diminished executive functioning, impulsivity, being male, sleep-related issues, unemployment, loss of support system, social isolation, and changes in family dynamics [34]. Some research suggests that individuals with TBI attempt suicide by overdosing on prescription medications [33]. Due to this dangerous potential, probation officers and the client's support system should be aware of warning signs for self-harm and suicidal behaviors [34]. If a client with TBI attempts suicide, they should be carefully monitored for continued issues over at least the course of the following year. Interventions that address a specific client's needs in neurology, psychology, and social functioning through 
therapy (e.g., rehabilitation, coping strategies, psychoeducation, and daily life management skills), support groups, and medication hold the most promise [34].

\section{Concentration impairments}

The concentration impairments of TBI can have a range of devastating consequences. Inattention and difficulty focusing are common deficits experienced after a mild traumatic brain injury such as a concussion [35]. These injuries can produce challenges in understanding instructions and regulations, which can result in poor performance and rule compliance in probation settings. Additionally, individuals with TBI often have impaired reading comprehension levels and slowed reading and writing abilities [36]. This places them at risk of not understanding documents that need to be read and signed. This often results in probationers being viewed as non-compliant and may be a factor when a probation violation occurs. As such, probation professionals should modify supervision approaches to be aware of the concentration deficits experienced by probationers impacted by TBI.

\section{Communication deficits}

Traumatic brain injury can cause trauma in many different areas of the brain, including areas that generate and comprehend speech [37]. Such impairments can manifest themselves in several ways including the art of conversation, where the individual may have difficulty speaking, listening, and comprehending information, leading to increased frustration and a compromised social network [38]. Beyond this, individuals with TBI may have issues with detecting social cues, maintaining eye contact, violating the norms of personal space, and demonstrating empathy. As a result, probationers with a TBI may misunderstand directions, guidelines, and expectations due to their deficits. To limit such potential consequences, probation officers should speak slowly, clearly, and keep it simple. Probation officers may need to explore alternative means to aid in successful communication with the probationer. With increased reporting and frequent check-ins, probationers may also have opportunities to be reminded about their conditions and expectations. When placing this population in programming, be aware of interpersonal communication complications and the challenges that the client may encounter.

\section{Memory impairments}

Memory deficits are among the most frequently reported cognitive impairments after traumatic brain injury [39]. The prevalence of memory impairment after traumatic brain injury is more than $60 \%$ [40]. Common injuries such as frontal lobe damage associated with acceleration-deceleration injuries can cause diffuse axonal injury leading to impaired memory for daily activities and goal driven activities, such as planning and execution of arriving at an appointment [41]. These impairments can take the form of both shortand long-term memory issues including suggestibility and confabulation, which present challenges in criminal justice settings. Some areas where these memory impairments can potentially contribute to supervision issues are treatment, medication, and appointment compliance [4]. Specifically, clients with TBI may simply have difficulty remembering appointments and their medication schedule. In turn, frequent reminders, compliance checks, and monitoring of treatment medication side effects are extremely important. Additionally, individuals with TBI have difficulty learning, remembering, and comprehending the rules of probation. When TBI is present, probation officers are encouraged to find alternate methods to aid their clients in remembering the rules of probation or supervision [42]. Considering TBI-related challenges and possible mental health diagnoses as mitigating factors, probation officers should attempt to investigate if poor performance and rule infractions are willful or resulting from these issues prior to violating a client.

\section{Learning problems}

Learning problems are a common deficit associated with TBI. Traumatic brain injury often results in diffuse axonal injury, which is the disconnection between the neurons within associating brain networks. Injuries affecting the frontal lobes often result in organizational deficits that cause issues with written and verbal expression, attention, and concentration [43]. Traditional intervention and treatment programs may not recognize or address learning challenges among these impacted individuals. If learning deficits are not addressed, individuals with TBI may be incapable of comprehending crucial treatment interventions [44]. It is critical for probation professionals and treatment providers to recognize TBIrelated deficits and modify intervention and treatment approaches to meet the needs of this special group of clients.

\section{Physical impairments}

TBI can have many physical symptoms including pervasive headaches and migraines, physical weakness and coordination problems (e.g., numbness, dizziness, clumsiness, and balance issues), sleep issues (e.g., drowsiness and insomnia), sensory impairment (e.g., loss of sense of smell, taste, and vision), and chronic pain. Many times, physical impairments will present along with the cognitive and emotional impairments [45]. Light sensitivity and loud noises can also create some issues for this population. Living with these symptoms and/or impairments has a significant impact on the probationer's emotional stability [46]. Probationers may have physical disabilities that need to be taken into consideration regarding probation requirements such as being a fall risk or having paralysis. Probation officers should question the probationer about visible marks and bruises; especially, if they are a common occurrence. It would also be important to consider if they are frequenting hospitals and emergency rooms if that information is available. These diverse challenges should bring awareness to probation officers regarding their surroundings when talking to clients who may have TBI.

\section{Mobility issues}

Physical coordination and maintaining equilibrium are essential abilities for typical daily activities like walking, driving, working, and exercising [22]. Problematically, TBI can have a profound impact on physical coordination and maintaining equilibrium, resulting in difficulties performing everyday tasks [45]. For example, activities such as a riding a bike may become hazardous to the client after suffering a TBI, even though the client previously had no issues with this activity. Although many of those who have sustained severe traumatic brain injuries have undergone long rehabilitation processes to gain back mobility and coordination, these faculties are often still compromised [45]. These issues are magnified in challenging settings like the criminal justice system where the risk for injury and victimization are high. 
Page 4 of 9

\section{Impulsiveness}

Impulsivity is common among individuals with TBI and contributes to involvement in the criminal justice system. Frontal lobe head trauma causes damage to the "braking" area of the brain, resulting in individuals acting on impulse and emotion [47]. Poor impulse control commonly brings about irritability, aggression, loss of temper, and poor decision making, which may impede rehabilitation [48]. In short, individuals with TBI often lack the ability to think ahead and see the consequences of their actions. Considering these high levels of impulsivity, clients with TBI may become confused about why they are in violation of probation and may not comprehend what went wrong.

\section{Aggression}

The behavioral disinhibition that frequently accompanies a traumatic brain injury [49] increases the likelihood of aggressive behavior [50]. Many factors including gender, age at the time of the TBI, presence of frontal lobe lesions, and conditions prior to the TBI (e.g., cognitive skills, substance use, aggressiveness, and history of mental health issues like mood and anxiety disorders) all predispose an individual to aggression after a TBI [51]. Clinically, there are different types of aggressive behavior that can occur sometimes after the individual has sustained TBI. In many instances, aggressive behaviors that occur post-TBI result from impulse control problems [52]. When present, this type of behavior can be long-lasting, with many probationers struggling with the unknown of a situation, especially when potentially facing a violation. This may increase the probationer's irritability, aggression, or loss of temper. Due to the lack of ability to think ahead and foresee the consequences of their actions, the probationer may end up resisting arrest or assaulting officers, particularly when an officer's actions are perceived as aggressive or unfair [53]. Probation officers should use caution when interacting with probationers and be conscious of how they are being perceived by the probationers. Additionally, probation officers should work to ensure that their clients receive appropriate assessments and treatments. This will likely require contact with the client's physician to gain insight into the client's condition and treatment progress. All of this information can help inform the probation officer's interactions with their clients and the supervision strategy as a whole.

\section{Substance abuse}

Traumatic brain injury can increase the risk of substance abuse. It is estimated that as many individuals with TBI have a co-occurring substance abuse diagnosis [44]. Traumatic brain injury and substance abuse are co-occurring in a record number of offenders [54-56]. For example, over $80 \%$ of jail inmates report having a history of at least one incident of head trauma in their past [44] and inmates with TBI are over two times more likely to use illicit drugs than inmates without TBI [57]. Alcohol misuse is often linked with TBI as alcohol intoxication is a proximate cause of a large subset of injuries, leading to more than half of TBI instances being directly or indirectly caused by alcohol use [58]. When substance abuse is present in clients with TBI, cognitive impairments including disinhibition, decision making deficits, and high-risk behaviors may increase [55]. Such neuropsychological impairments appear to be more pronounced in the presence of both TBI and substance abuse than when only one of these conditions is present [59]. To protect against this possibility, probationers should be screened for substance abuse, as the use of drugs can only exacerbate emotional and behavioral dyscontrol.

\section{Emotional immaturity}

Traumatic brain injuries can stunt the development of emotional maturity at the point in time when the injury was sustained. This is particularly relevant when the TBI occurred during childhood or adolescence [60]. After the injury, emotional growth may slow and hover around the age when the injury took place. As a result, the individual may act and make decisions like a person younger than their actual age in many instances, displaying characteristics of an immature child including impulsivity, inflexibility, and impatience [61]. As such, it is important to understand this disconnect between emotional age and chronological age when dealing with probationers who have sustained a traumatic brain injury. For example, a client who is 40 years old may have the emotional maturity of a 15 -year-old. Additionally, traumatic brain injury in early life is associated with poor language competency, non-verbal communication, and slowed processes that are linked to the development of social skills [62]. In such instances, probation officers should help ensure that the level of communication and intervention approaches are suitable for the client's emotional maturity.

\section{Inappropriate social boundaries}

Offenders with TBI often have difficulty interacting with others due to emotional dysregulation, poor cause-effect thinking, social overstimulation, and limited social skills (e.g., inability to establish and maintain relationships and boundary issues). As a result, offenders with TBI have been associated with lower ability to maintain rule abiding behavior during incarceration and have higher rates of incarceration [63]. Individuals with TBI often exhibit socially inappropriate behaviors and have difficulty adapting behavior in social contexts by applying learned rules of appropriateness [61]. For example, sexual inappropriateness may emerge due to a lack of ability to "put the brakes" on their behavior or because they misinterpret or do not recognize social cues. This may stem from trauma-induced deficits in the frontal lobe, resulting in acting on emotion and impulse for immediate satisfaction. Alternatively, probationers with TBI are also incredibly prone to manipulation by others, which can result in them taking the blame for actions committed by others or committing acts that they never would have committed by themselves [32]. Considering these potential issues, probation officers should become familiar with their client's level of social competency, which may be quite lower than their chronological age. Along these lines, the probation officer may find it beneficial to learn about the client's social circle and ensure that they develop a strong pro-social support system. Further inquiry into their social activities can help gauge if they identify more closely with peer aged individuals or younger individuals. This process will require communicating with sources other than the client, as TBI is characterized by memory issues that limit the quality of self-reported information [32].

\section{Poor executive functioning abilities}

Traumatic brain injuries (TBI) are characterized by executive function impairments [64]. These impairments can include short- and long-term memory deficits, diminished attention capacity, impulsivity, poor self-control, apathy, and limitations in self-reflection $[42,65,66]$. Consequences of executive function impairments often take the form of difficulty understanding cause and effect and poor judgment, decision-making, and problem solving. Individuals with TBI may also display concrete thinking and egocentricity [61]. As such, probation officers should expect that clients with TBI may have poor planning 
Page 5 of 9

abilities and follow through that will limit their ability to complete complicated courses of action. This will make it difficult for the client to comply with the rules of probation and maintain steady employment. These clients will benefit from probation officers that recognize the executive function impairments and, in turn, assist them in overcoming their barriers [42]. This assistance can take the form of ensuring the client receives a thorough assessment and psychological care along with structural assistance to keep appointments and court dates.

\section{Sleep problems}

Frequently, criminal justice professionals and mental health providers are unaware of the links between TBI and issues of sleep. Psychological fatigue is defined as related to weakness, sleepiness, anhedonia, extended mental activity, and lack of energy [67]. As many as eighty percent of individuals report sleep changes after sustaining a TBI relative to $23 \%$ of the general population [68]. Specifically, individuals with a traumatic brain injury frequently report experiencing insomnia, more nighttime awakenings, longer sleep onset latency, and increased levels of anxiety and depression that interfere with sleep [68]. Sleep-related problems among this population can create a host of problems that negatively interfere with the individual's ability to successfully comply with rules of probation [69]. Probation officers are encouraged to modify approaches to consider the additional deficits that can result from TBI-related sleep problems. Foremost among these steps is referring impacted individuals to a qualified healthcare provider who can properly evaluate and treat sleep-related problems caused by TBI [70].

\section{Poor information retention}

Individuals with TBI have difficulty retaining information. Many suffer from anosognosia, the inability to see the "big picture" and anticipate the consequences of their actions. The onset of anosognosia after a TBI typically involves behavioral, cognitive, and emotional disorders with a tendency towards positive self-evaluation and the avoidance of adverse information [71]. For example, individuals with TBI commonly have a diminished ability to understand the consequences of not complying with probation. This can lead to higher recidivism rates because of impulsivity and the inability to learn from previous mistakes [72]. Frank discussions about behavior and actions can benefit individuals who are not adept at recognizing the consequences of their choices. Probation officers should expect that they will have to repeat information several times throughout the course of supervision. Probationers may continually ask the same questions due to the lack of information retention [72]. It is helpful to provide probationers with visual aids to assist with information processing and retention (e.g., performing a cost-benefit analysis, thought-feeling-action link, or other workbook style supervision tool).

\section{Impaired self-awareness}

Individuals with TBI often suffer from a lack of self-awareness. This may present to the probation officer as a lack of interest in completing treatment successfully or complying with rules of probation. However, these behaviors may simply be the result of TBI. This may be especially prevalent in the juvenile population as juvenile offenders are at 3.38 times higher odds of having a traumatic brain injury than the general population [13]. This lack of self-awareness may also increase the likelihood that the individual with TBI will struggle with grasping the extent of their symptoms and overcoming them $[73,74]$. To combat these difficulties, individuals with TBI should be taught about their symptoms and how to overcome these symptoms through treatment [17]. A stumbling block in this process may be denial or a lack of coping skills [75].

\section{Confabulation}

Deficits caused by TBI may increase the risk of confabulation among [76]. Confabulation occurs when an individual provides inaccurate information based on false memories without the intention to deceive [77-80]. In other words, the individual believes that these incorrect memories are the truth, which is why this has been referred to as "honest lying" [81]. This can take the form of distortions of actual recollections to the large-scale fabrication of information with no basis in reality [82]. Although the etiology of confabulation is unclear, the mechanisms underlying the phenomenon are generally considered complicated. Particularly, TBI's seem to increase the risk of confabulation, but confabulation can still occur in individuals with no such injuries or other impairments [83]. Not only may correctional clientele be more likely to have suffered from a TBI, they could also be at risk to confabulate. As such, probation officers need to consider this possibility and avoid asking the probationer leading or misleading questions. Additionally, probation officers should avoid relying solely on self-reported information from the client whenever possible. Collateral sources of information including official records, health care providers, family members, and friends should be contacted to verify information. Failure to utilize collateral sources of information could result in inaccurate or inconsistent information ending up influencing important processes like a pre-sentence investigation (PSI). Remembering that confabulation is not intentional and referring clients for thorough neuropsychological evaluations are also of paramount importance [84].

\section{Screening and Assessment}

Improving the screening and assessment of TBI in criminal justice settings is imperative, particularly at entry points to the criminal justice system like probation. To enable this, probation departments must launch training programs to improve the familiarity of staff with the symptoms and consequences of TBI [85]. In fact, it may even be helpful for probation officers to adopt an approach where they consider the presence of TBI to be the rule rather than the exception. This section highlights several considerations for probation officers when confronted with the possibility of TBI among probationers.

A thorough evaluation is a necessary first-step when an individual is being sentenced to probation during the pre-sentence investigation or later during intake to probation. This evaluation should include a complete medical, psychosocial, and neurological assessment of the individual [86]. The possible presence of TBI must be carefully considered throughout this evaluation. This process will not be easy [53], as individuals with TBI often have co-occurring psychiatric and substance use disorders along with a history of misdiagnosis. Considering these diagnostic difficulties, it would be beneficial to view the presence of substance abuse, domestic violence, military service, and athletic history as warning signs that warrant a thorough assessment of the potential presence of TBI.

When these warning signs or evidence of a head injury are present, probation officers should explore if there have been any potential impacts on cognitive functioning, personality, and behavior [32]. Determining the lingering aspects or long-term effects are particularly 
challenging. In some cases where the TBI occurred during childhood, the presence of changes in brain functioning may not have even been apparent until several years later. In many cases, cognitive and learning deficits might not emerge until middle school or high school when greater educational demands are present [87]. As such, this decreases the likelihood that TBI was properly identified as the cause of the emerging issues.

Even in such difficult instances when the TBI occurred decades before, one way that probation officers can have a profound impact on their success in gathering accurate information is how they ask about the presence of TBI [18]. Avoiding the use of official medical terminology is an important strategy to consider. For example, the probation officer may not get an accurate response if they ask a client if they have ever suffered a traumatic brain injury. However, the probation officer could be more likely to receive an accurate response if they ask the client if they have ever been knocked out or suffered a concussion in a car accident or playing football [18]. Once the client is on the same page, the probation officer will likely be more effective in eliciting useful information through follow-up questioning.

Nonetheless, the veracity of information self-reported by the client is cast in doubt by the associated symptoms of TBI's. Specifically, the short- and long-term memory impairments of TBI make it difficult to rely solely on information obtained from the client when making important supervision and treatment decisions [84]. As such, probation officers must seek out collateral sources of information like official records, other professionals familiar with the client, family members, and peers. If the information from the client can be verified by these alternative sources, then the probation officer can be much more comfortable making decisions that affect the client [88].

Thorough and accurate diagnosis can better enable criminal justice professionals to effect positive change in clients with TBI [63]. Such information allows criminal justice professionals to better tailor supervision and treatment plans to manage the client's risk of recidivism [23]. Early recognition of TBI only improves the likelihood of intervention success. Despite these benefits, TBI is still commonly overlooked in probation settings, which decreases the effectiveness of supervision and treatment plans and results in higher rates of recidivism among clients with TBI [89].

\section{Discussion}

\section{Interventions, supports, and services}

Probationers with TBI will likely struggle to benefit from typical intervention and treatment approaches. The symptoms of TBI like attention and memory deficits make it difficult to participate in and maintain engagement in psychological treatment. Complicating matters, probationers with TBI often present with comorbid psychiatric, substance use, and neurological disorders [2]. Not only does this complex clinical picture make interventions more difficult, but the available treatment programs and resources in the surrounding community may not be an adequate fit for the client [11]. Nonetheless, ensuring that probationers with TBI receive adequate and responsive treatment and services is imperative because insufficient care places the client at risk for worsening symptoms and an increased likelihood of recidivism [57]. To this end, there is a strong need for the systematic development of TBI-focused treatment options in community corrections settings across the nation.
Early identification and interventions hold the most promise for probationers with TBI. After a thorough assessment and diagnostic process, a comprehensive treatment plan should be developed to focus on the individual's risks and needs [5]. For example, a probationer with anger issues may benefit from anger management treatment. Further, treatment should focus on reducing any behaviors that may have contributed to the client suffering the TBI to curtail the possibility of subsequent TBI's. Vocationally, probationers need evidence-based frameworks for evaluation and placement as their cognitive and/or physical abilities are compromised [90]. Regardless of the established success of a treatment program in corrections settings, the treatment will likely need to be adjusted to account for the unique needs of clients with TBI. Any programming should be feasible for the client to participate in and complete considering their capabilities. Ongoing screening should be a part of the treatment and supervision plans to help ensure that the client's diverse and evolving needs are addressed [5]. When done with fidelity, such programming can help prevent the development or exacerbation of secondary conditions and decrease the likelihood of continued criminal justice-involvement [91].

Not to be neglected is the client's support system (i.e., care providers, family, caregivers, and friends). Because clients with TBI's may not fully recover their social and financial independence, many will have to rely on the support of friends and family [92]. As such, probation officers will need to verify if the client has a strong enough support system to meet their needs. Resources to help support system members become more familiar with TBI are warranted. Without the backing of a sufficient support system, clients with TBI are more likely to have their symptoms worsen and secondary conditions like mental illness and substance abuse may emerge [93]. To ensure everyone is on the same page, probation officers should regularly communicate with key members of the support system about the expectations and requirements of probation and treatment when appropriate releases have been signed by the client [94].

These endeavors will require a significant expenditure of the probation officer's time. It is no small investment to ensure that a client with TBI has adequate supervision, treatment, education, and supports [95]. This will require helping the client remain organized and accountable despite their TBI-related impairments. This may take the form of helping the client overcome memory deficits by writing down step-by-step instructions and appointments and conducting meetings in calm environments with minimal distractions [96]. Through such diligence, the probation officer can help the client maximize their chances of successfully completing treatment and avoiding further entanglements in the criminal justice system [97]. To increase the likelihood that probation officers can meet these demands, ongoing training and education in TBI and relevant skills like interviewing techniques are imperative.

\section{Conclusion}

Traumatic brain injuries can be permanent conditions that cause some individuals to become involved in the criminal justice system. Unfortunately, individuals with TBI are ill equipped to navigate the criminal justice system. For example, the individual could make poor legal decisions like waiving the right to an attorney, falsely confessing to a crime, or not assisting their lawyer during their trial. As such, individuals with TBI are often convicted of crimes and sentenced to serve a period of time on probation. Once on probation, individuals with TBI will likely have some difficulty meeting the requirements of probation such as attending appointments, completing treatment, and 
Page 7 of 9

maintaining employment. There are many deficits associated with TBI that impact a probationer in their ability to understand and follow through with probation requirements. Impairments such as cognitive skills, executive functioning, emotional immaturity, and impulsiveness can result in consequential action that is counterproductive to the probationer. Probation officers are in a unique position to assist such individuals in understanding requirements and behavioral action geared to successful reintegration into society. To help prevent these issues, it is essential that probation officers fully understand the implications and deficits associated with TBI. However, this requires specific education and training focused upon the causes, symptoms, and warning signs of TBI. Another area of training should focus on individualizing supervision within a risk-needs-responsivity framework, which is an evidence-based practice proven to positively impact recidivism rates. Finally, probation officers should receive training in how to establish relationships and work with medical and treatment professionals to ensure that their clients receive adequate care. Awareness, education, and training in these areas among probation officers are crucial to more successfully work with this population. With such appropriate services and supports, the client will be more likely to successfully complete probation.

\section{References}

1. https://www.cdc.gov/traumaticbraininjury/index.html

2. Shiroma EJ, Ferguson PL, Pickelsimer EE (2010) Prevalence of traumatic brain injury in an offender population: A meta-analysis. J Correct Health Care 16: 147-159.

3. Silver JM, Kramer R, Greenwald S, Weissman M (2001) The association between head injuries and psychiatric disorders: findings from the New Haven NIMH Epidemiologic Catchment Area Study. Brain Inj 15: 935-945.

4. Ray B, Richardson NJ (2017) Traumatic brain injury and recidivism among returning inmates. Crim Justice Behav 44: 472-486.

5. Brown J, Louie P (2017) Perceptions of traumatic brain injury among public defenders in the state of Minnesota. J Forensic Res 8: 1-6.

6. Goldstein M (1990) Traumatic brain injury: a silent epidemic. Ann Neurol 27: 327.

7. Langlois JA, Rutland-Brown W, Wald MM (2006) The epidemiology and impact of traumatic brain injury. J Head Trauma Rehabil 21: 375-378.

8. Lengenfelder J, Arjunan A, Chiaravalloti N, Smith A, DeLuca J (2015) Assessing frontal behavioral syndromes and cognitive functions in traumatic brain injury. Appl Neuropsychol Adult 22: 7-15.

9. Vaughn MG, Salas-Wright CP, DeLisi M, Perron B (2014) Correlates of traumatic brain injury among juvenile offenders: A multi-site study. Crim Behav Ment Health 24: 188-203.

10. Misic-Pavkov G, Novovic Z, Bozic K, Kolundzija K, Kovacevic SI, et al. (2012) Forensic aspect of late subjective complaints after traumatic brain injury. Eur Rev Med Pharmacol Sci 16: 1806-1813.

11. Slaughter B, Fann JR, Ehde D (2003) Traumatic brain injury in a county jail population: prevalence, neuropsychological functioning and psychiatric disorders. Brain Inj 17: 731-741.

12. Farrer TJ, Hedges DW (2011) Prevalence of traumatic brain injury in incarcerated groups compared to the general population: a metaanalysis. Prog Neuropsychopharmacol Biol Psychiatry 35: 390-394.

13. Farrer TJ, Frost RB, Hedges DW (2013) Prevalence of traumatic brain injury in juvenile offenders: A meta-analysis. Child Neuropsychol 19: 225-234.

14. Stewart LA, Wilton G, Sapers J (2016) Offenders with cognitive deficits in a Canadian prison population: Prevalence, profile, and outcomes. Int J Law Psychiatry 44: 7-14.
15. Johnson LD (2009) Guilty or innocent. Just take a look at my brainanalyzing the nexus between traumatic brain injury and criminal responsibility. SUL Rev 37: 25.

16. Ketter AH, Gordon W, Spielman L, Sy KT, Beckworth B (2016) Texas juvenile justice traumatic brain injury screening project part I. Archives of Physical Medicine and Rehabilitation 97: e32.

17. Horn ML, Lutz DJ (2016) Traumatic brain injury in the criminal justice system: Identification and response to neurological trauma. Applied Psychology in Criminal Justice 12: 71-86.

18. Hux K, Schneider T, Bennett K (2009) Screening for traumatic brain injury. Brain Inj 23: 8-14.

19. Andrews DA, Bonta J, Hoge RD (1990) Classification for effective rehabilitation: Rediscovering psychology. Crim Justice Behav 17: 19-52.

20. American Psychiatric Association (2013) Diagnostic and statistical manual of mental disorders (5th edn). Washington DC, USA.

21. Edwards WJ, Greenspan S (2011) Adaptive behavior and fetal alcohol spectrum disorders. J Psychiatry Law 38: 419-447.

22. Ilie G, Mann RE, Ialomiteanu A, Adlaf EM, Hamilton H, et al. (2015) Traumatic brain injury, driver aggression and motor vehicle collisions in Canadian adults. Accident Analysis Prevention 81: 1-7.

23. Williams WH, Cordan G, Mewse AJ, Tonks J, Burgess CN (2010) Selfreported traumatic brain injury in male young offenders: A risk factor for reoffending, poor mental health, and violence. Neuropsychol Rehabil 20: 801-812.

24. Zgaljardic DJ, Seale GS, Schaefer LA, Temple RO, Foreman J, et al. (2015) Psychiatric disease and post-acute traumatic brain injury. J Neurotrauma 32: 1911-1925.

25. Juengst SB, Arenth PM, Whyte EM, Skidmore ER (2014) Brief report of affective state and depression status after traumatic brain injury. Rehabil Psychol 59: 242-246.

26. Brenner LA, Ignacio RV, Blow FC (2011) Suicide and traumatic brain injury among individuals seeking Veterans Health Administration services. J Head Trauma Rehabil 26: 257-264.

27. Simpson G, Tate R (2007) Suicidality in people surviving a traumatic brain injury: prevalence, risk factors and implications for clinical management. Brain Inj 21: 1335-1351.

28. Simpson GK, Tate RL (2007) Preventing suicide after traumatic brain injury: Implications for general practice. Med J Aust 187: 229-232.

29. Harrison-Felix CL, Whiteneck GG, Jha A, DeVivo MJ, Hammond FM, et al. (2009) Mortality over four decades after traumatic brain injury rehabilitation: a retrospective cohort study. Arch Phys Med Rehabil 90: 1506-1513.

30. Mackelprang JL, Bombardier CH, Fann JR, Temkin NR, Barber JK, et al. (2014) Rates and predictors of suicidal ideation during the first year after traumatic brain injury. Am J Public Health 104: e100-e107.

31. Teasdale TW, Engberg AW (2001) Suicide after traumatic brain injury: A population study. J Neurol Neurosurg Psychiatry 71: 436-440.

32. Ashman TA, Gordon WA, Cantor JB, Hibbard MR (2006) Neurobehavioral consequences of traumatic brain injury. Mt Sinai J Med 73: 999-1005.

33. Simpson G, Tate R (2005) Clinical features of suicide attempts after traumatic brain injury. J Nerv Ment Dis 193: 680-685.

34. Nowrangi MA, Kortte KB, Rao VA (2014) A perspectives approach to suicide after traumatic brain injury: Case and review. Psychosomatics 55: 430-437.

35. Bonnelle V, Leech R, Kinnunen KM, Ham TE, Beckmann CF, et al. (2011) Default mode network connectivity predicts sustained attention deficits after traumatic brain injury. J Neurosci 31: 13442-13451.

36. Sohlberg MM, Griffiths GG, Fickas S (2014) An evaluation of reading comprehension of expository text in adults with traumatic brain injury. American Journal of Speech Language Pathology 23: 160-175.

37. Sharp DJ, Scott G, Leech R (2014) Network dysfunction after traumatic brain injury. Nature Reviews Neurology 10: 156-166. 
38. Fried-Oken M, Beukelman DR, Hux K (2012) Current and future AAC research considerations for adults with acquired cognitive and communication impairments. Assist Technol 24: 56-66.

39. Carlozzi N E, Grech J, Tulsky DS (2013) Memory functioning in individuals with traumatic brain injury: An examination of the Wechsler Memory Scale-Fourth Edition (WMS-IV). J Clin Exp Neuropsychol 35: 906-914.

40. Larsson J, Björkdahl A, Esbjörnsson E, Sunnerhagen KS (2013) Factors affecting participation after traumatic brain injury. J Rehabil Med 45: 765-770.

41. Wright MJ, Wong AL, Obermeit LC, Woo E, Schmitter-Edgecombe M, et al. (2014) Memory for performed and observed activities following traumatic brain injury. J Clin Exp Neuropsychol 36: 268-277.

42. Bernett AA (2012) Traumatic brain injury and executive functioning in an incarcerated sample. Available from ProQuest Dissertations. (UMI No. 1434728).

43. Wheeler L, Nickerson S, Long K, Silver R (2014) Expressive writing in people with traumatic brain injury and learning disability. NeuroRehabilitation 34: 29-37.

44. Buck PW (2011) Mild traumatic brain injury: A silent epidemic in our practices. Health Soc Work 36: 299.

45. Fritz NE, Basso DM (2013) Dual-task training for balance and mobility in a person with severe traumatic brain injury: a case study. J Neurol Phys Ther 37: 37-43.

46. Soberg HL, Finset A, Roise O, Bautz-Holter E (2012) The trajectory of physical and mental health from injury to 5 years after multiple trauma: A prospective, longitudinal cohort study. Arch Phys Med Rehabil 93: 765-774.

47. Todd K (2010) A neuropsychological study of traumatic brain injury among a Canadian sample of male federal offenders. (Doctoral thesis, University of Regina, Saskatchewan).

48. Rochat L, Beni C, Annoni JM, Vuadens P, Van der Linden M (2013) How inhibition relates to impulsivity after moderate to severe traumatic brain injury. J Int Neuropsychol Soc 19: 890-898.

49. Arciniegas DB, Wortzel HS (2014) Emotional and behavioral dyscontrol after traumatic brain injury. Psychiatr Clin North Am 37: 31-53.

50. Rao V, Rosenberg P, Bertrand M, Salehinia S, Spiro J, et al. (2009) Aggression after traumatic brain injury: prevalence and correlates. J Neuropsychiatry Clin Neurosci 21: 420-429.

51. Baguley IJ, Cooper J, Felmingham K (2006) Aggressive behavior following traumatic brain injury: how common is common? J Head Trauma Rehabil 21: 45-56.

52. Bresler S, Scalora MJ, Elbogen EB, Moore YS (2003) Attempted suicide by cop: A case study of traumatic brain injury and the insanity defense. J Forensic Sci 48: 1-5.

53. Colantonio A, Stamenova V, Abramowitz C, Clarke D, Christensen B (2007) Brain injury in a forensic psychiatry population. Brain Inj 21: 1353-1360.

54. Felde AB, Westermeyer J, Thuras P (2006) Co-morbid traumatic brain injury and substance use disorder: childhood predictors and adult correlates. Brain Inj 20: 41-49.

55. Fishbein D, Dariotis JK, Ferguson PL, Pickelsimer EE (2016) Relationships between traumatic brain injury and illicit drug use and their association with aggression in inmates. Int J Offender Ther Comp Criminol 60: 575-597.

56. Walker R, Hiller M, Staton M, Leukefeld CG (2003) Head injury among drug abusers: an indicator of co-occurring problems. J Psychoactive Drugs 35: 343-353.

57. Schofield PW, Butler TG, Hollis SJ, Smith NE, Lee SJ, et al. (2006) Traumatic brain injury among Australian prisoners: Rates, recurrence and sequelae. Brain Inj 20: 499-506.

58. Weil ZM, Corrigan JD, Karelina K (2016) Alcohol abuse after traumatic brain injury: experimental and clinical evidence. Neurosci Biobehav Rev 62: 89-99.
59. Barnfield TV, Leathem JM (1998) Neuropsychological outcomes of traumatic brain injury and substance abuse in a New Zealand prison population. Brain Inj 12: 951-962.

60. Root AE, Wimsatt M, Rubin KH, Bigler ED, Dennis M, et al. (2016) Children with traumatic brain injury: Associations between parenting and social adjustment. J Appl Dev Psychol 42: 1-7.

61. Wheeler S (2014) Approaches to managing executive cognitive functioning impairment following TBI: A focus on facilitating community participation. InTech.

62. Ryan NP, Catroppa C, Godfrey C, Noble-Haeusslein LJ, Shultz SR, et al. (2016) Social dysfunction after pediatric traumatic brain injury: A translational perspective. Neurosci Biobehav Rev 64: 196-214.

63. Piccolino AL, Solberg KB (2014) The impact of traumatic brain injury on prison health services and offender management. J Correct Health Care 20: 203-212.

64. Homaifar BY, Brenner LA, Forster JE, Nagamoto H (2012) Traumatic brain injury, executive functioning, and suicidal behavior: A brief report. Rehabil Psychol 57: 337-341.

65. Lipton ML, Gulko E, Zimmerman ME, Friedman BW, Kim M, et al. (2009) Diffusion tensor imaging implicates prefrontal axonal injury in executive function impairment following very mild traumatic brain injury. Radiology 252: 816-824.

66. Little DM, Kraus MF, Joseph J, Geary EK, Susmaras T, et al. (2010) Thalamic integrity underlies executive dysfunction in traumatic brain injury. Neurology 74: 558-564.

67. Belmont A, Agar N, Hugeron C, Gallais B, Azouvi P (2006) Fatigue and traumatic brain injury. Ann Readapt Med Phys 49: 370-374.

68. Ponsford JL, Ziino C, Parcell DL, Shekleton JA, Roper M, et al. (2012) Fatigue and sleep disturbance following traumatic brain injury their nature, causes, and potential treatments. J Head Trauma Rehabil 27: 224-233.

69. Singh K, Morse AM, Tkachenko N, Kothare SV (2016) Sleep disorders associated with traumatic brain injury-a review. Pediatr Neurol 60: 30-36.

70. Englander J, Bushnik T, Oggins J, Katznelson L (2010) Fatigue after traumatic brain injury: Association with neuroendocrine, sleep, depression, and other factors. Brain Inj 24: 1379-1388.

71. Gasquoine PG (2016) Blissfully unaware: Anosognosia and anosodiaphoria after acquired brain injury. Neuropsychol Rehabil 26: 261-285.

72. Phillips NL, Parry L, Mandalis A, Lah S (2017) Working memory outcomes following traumatic brain injury in children: A systematic review with meta-analysis. Child Neuropsychol 23: 26-66.

73. Baldry E, Clarence M, Dowse L, Trollor J (2013) Reducing vulnerability to harm in adults with cognitive disabilities in the Australia criminal justice system. J Policy Practice Intellect Disabilities 10: 222-229.

74. Ownsworth TL, McFarland K, Young RM (2002) The investigation of factors underlying deficits in self-awareness and self-regulation. Brain Inj 16: 291-309.

75. Blair RJ, Cipolotti L (2000) Impaired social response reversal: A case of 'acquired sociopathy'. Brain 123: 1122-1141.

76. Brown J, Huntley D, Asp E, Fabrizio K, Wiley C, et al. (2016) Traumatic brain injury and confabulation: An introduction for criminal justice and legal professionals. J Special Population 1: 1-13.

77. Ackil JK, Zaragoza MS (1998) Memorial consequences of forced confabulation: Age differences in susceptibility to false memories. Dev Psychol 34: 1358-1372.

78. Anastasi JS (2006) Understanding confabulation: A multidisciplinary approach. Appl Cognit Psychol 20: 275-278.

79. Clare IC, Gudjonsson GH (1993) Interrogative suggestibility, confabulation, and acquiescence in people with mild learning disabilities (mental handicap): Implications for reliability during police interrogations. Br J Clin Psychol 32: 295-301.

80. Fotopoulou A, Conway MA, Solms M (2007) Confabulation: Motivated reality monitoring. Neuropsychologia 45: 2180-2190. 
Citation: Brown J, Luckhardt B, Harr D, Poser T, Fenrich A (2018) Traumatic Brain Injury (TBI): A Guide for Probation Officers. J Trauma Treat 7:

Page 9 of 9

81. Moscovitch M (1989) Confabulation and the frontal system: Strategic versus associative retrieval in neuropsychological theories of memory. In Roedinger HL, Craik FI (Eds.), Varieties of memory and consciousness: Essays in honour of Endel Tulving. Hillsdale, NJ: Lawrence Erlbaum Associates Inc.

82. Brown J, Hesse M, Rosenbloom M, Harris B, Weaver J, et al. (2014) Confabulation in correctional settings: An exploratory review. Journal of Law Enforcement 4: 1-8.

83. Moscovitch M (1995) Confabulation. In Schacter DL (ed), Memory distortions (pp. 226-251). Cambridge, MA: Harvard University Press.

84. Brown J, Charette C, Huntley D, Wartnik AP, Wiley CR, et al. (2017) Confabulation: A beginner's guide for legal professionals. Forensic Science and Criminology 2: 1-5.

85. Mancusi CE (2013) Traumatic brain injury as a risk factor for recidivism, CDC, USA.

86. Sweet JJ, Goldman DJ, Guidotti Breting LM (2013). Traumatic brain injury: Guidance in a forensic context from outcome, dose-response, and response bias research. Behav Sci Law 31: 756-778.

87. Anderson SW, Damasio H, Tranel D, Damasio AR (2000) Long-term sequelae of prefrontal cortex damage acquired in early childhood. Dev Neuropsychol 18: 281-296

88. Ylvisaker M, Todis B, Glang A, Urbanczyk B, Franklin C, et al. (2001) Educating students with TBI: Themes and recommendations. J Head Trauma Rehabil 16: 76-93.

89. Diamond PM, Magaletta PR, Harzke AJ, Baxter J (2008) Who requests psychological services upon admission to prison? Psychological Services 5: 97-107.
90. Andelic N, Sigurdardottir S, Arango-Lasprilla JC, Godbolt AK (2016) Long term functional and psychosocial consequences and health care provision after traumatic brain injury. Behav Neurol 1-3.

91. Gouick J, Gentleman D (2004) The emotional and behavioral consequences of traumatic brain injury. Trauma 6: 285-292.

92. Humphreys I, Wood RL, Phillips CJ, Macey S (2013) The costs of traumatic brain injury: A literature review. Clinicoecon Outcomes Res 5: 281-287.

93. Kim H, Colantonio A, Dawson DR, Bayley MT (2013) Community integration outcomes after traumatic brain injury due to physical assault. Can J Occup Ther 80: 49-58.

94. Matarazzo BB, Signoracci GM, Brenner LA, Olson-Madden JH (2016) Barriers and facilitators in providing community mental health care to returning veterans with a history of traumatic brain injury and cooccurring mental health symptoms. Community Ment Health J 52: 158-164.

95. Miller SC, Baktash SH, Webb TS, Whitehead CR, Maynard C (2013) Risk for addiction-related disorders following mild traumatic brain injury in a large cohort of active-duty US airmen. Am J Psychiatry 170: 383-390.

96. Spikman JM, Timmerman ME, Milders MV, Veenstra WS, van der Naalt J (2012) Social cognition impairments in relation to general cognitive deficits, injury severity, and prefrontal lesions in traumatic brain injury patients. J Neurotrauma 29: 101-111.

97. Wall KC (2017) Violence-related traumatic brain injury in justiceinvolved women. Doctoral Papers and Masters Projects. 